\title{
Diverse models for anti-HIV activity of purine nucleoside analogs
}

\author{
Naveen Khatri ${ }^{1}$, Viney Lather ${ }^{2}$ and A K Madan ${ }^{1 *}$
}

\begin{abstract}
Background: Purine nucleoside analogs (PNAs) constitute an important group of cytotoxic drugs for the treatment of neoplastic and autoimmune diseases. In the present study, classification models have been developed for the prediction of the anti-HIV activity of purine nucleoside analogs.

Results: The topochemical version of superaugmented pendentic index-4 has been proposed and successfully utilized for the development of models. A total of 60 2D and 3D molecular descriptors (MDs) of diverse nature were selected for building the classification models using decision tree (DT), random forest (RF), support vector machine (SVM), and moving average analysis (MAA). The values of most of these descriptors for each of the analogs in the dataset were computed using the Dragon software (version 5.3). An in-house computer program was also employed to calculate additional MDs which were not included in the Dragon software. DT, RF, and SVM correctly classified the analogs into actives and inactives with an accuracy of $89 \%, 83 \%$, and $78 \%$, respectively. MAA-based models predicted the anti-HIV activity of purine nucleoside analogs with a non-error rate up to $98 \%$. Therapeutic active spans of the suggested MAA-based models not only showed more potency but also exhibited enhanced safety as revealed by comparatively high values of selectivity index (SI). The statistical importance of the developed models was appraised via intercorrelation analysis, specificity, sensitivity, non-error rate, and Matthews correlation coefficient.

Conclusions: High predictability of the proposed models clearly indicates an immense potential for developing lead molecules for potent but safe anti-HIV purine nucleoside analogs.
\end{abstract}

Keywords: Anti-HIV activity, Superaugmented pendentic topochemical index, Balaban-type index from Z-weighted distance matrix, Moving average analysis, Purine nucleoside analogs, Support vector machine

\section{Background}

The drug design and development process involves the use of a variety of computational techniques, such as (quantitative) structure-activity relationships [(Q)SAR], molecular mechanics, quantum mechanics, molecular dynamics, and drug-receptor docking [1, 2]. (Q)SAR studies are based on the premise that biological response is a function of the chemical structure $[3,4]$. (Q)SAR models reveal a relationship between the structural characteristics of the compounds and their biological activity or environmental behavior [5, 6]. (Q)SAR models predict chemical behavior and simulate adverse effects in laboratory animals, tissues, and cells directly from the chemical structure. This will naturally minimize the need to conduct animal tests so as

\footnotetext{
* Correspondence: madan_ak@yahoo.com

${ }^{1}$ Faculty of Pharmaceutical Sciences, Pt. B. D. Sharma University of Health Sciences, Rohtak 124001, India

Full list of author information is available at the end of the article
}

to comply with the regulatory requirements for human health and eco-toxicology endpoints [7, 8]. The main hypothesis in (Q)SAR is that similar chemicals have similar properties, and even a minor structural change(s) will result in a change in property value(s) [9]. SAR represents classification models that are used when an empirical property is characterized in a $(+1 /-1)$ manner, such as soluble/insoluble, active/inactive, toxic/non-toxic, permeable/ impermeable, inhibitor/non-inhibitor, ligand/non-ligand, substrate/non-substrate, mutagen/non-mutagen, polar/ non-polar, or carcinogen/non-carcinogen [10-15]. In silico screening constitutes a vital cost-effective high-throughput process for providing a rapid indication of potential hazards for use in lead prioritization [16].

Machine learning (ML) constitutes a vital area of artificial intelligence (AI) in which models are simply generated by extracting rules and functions from relatively large datasets. ML comprises diverse methods and 
algorithms such as decision trees, general CHAID models, $k$-nearest neighbors, random forests, Bayesian methods, Gaussian processes, artificial neural networks (ANN), artificial immune systems, kernel algorithms, and support vector machines (SVMs). ML algorithms extract relevant information from empirical dataset through computational/statistical techniques and generate a set of rules, functions, or procedures that allow them to predict the properties of novel objects which have not been included in the learning set. (Q)SAR models derived through ML algorithms are subsequently applied during the drug development process so as to optimize the therapeutic activity, target selectivity, and related physico-chemical and biological properties of the selected molecules $[10,17,18]$. The advantage of AI approaches is that they can be easily applied to learn from examples and to evolve suitable prophesy models in spite of the limited understanding of the underlying molecular processes. The AI approach is also beneficial whenever computational simulations based on fundamental physical models are too expensive to perform $[19,20]$.

AIDS is one of the most urgent global health problems and is the leading cause of death in Africa and the fourth leading cause of death across the world. Highly active antiretroviral therapy (HAART) has gained considerable success in Western countries. The anti-HIV drug evolution process resembles a crystal ball and involves a plenty of astonishment, expectations, and disappointments. Unfortunately, we continue to be dependent on the predictions of the crystal ball. All of the currently available anti-HIV drugs are far from ideal, and we still face problems of acute and chronic side effects, patient compliance issues, drug resistance, cost, and potency. Hopes of long-term management and eradication depend on increasing available therapeutic options [21, 22].

Purine nucleoside analogs (PNAs) constitute an important group of cytotoxic drugs for the treatment of neoplastic and autoimmune diseases [23]. 9-[4- $\alpha-$ (Hydroxymethyl)cyclopent-2-ene-1- $\alpha$-yl]guanine (CBV), (-)- $\beta$-D-(2R,4R)-1,3-dioxolane-guanosine (DXZ), 3 ' -azido-3' deoxy-guanosine (AZG), and 2'-C-methylguanosine are all known for their reverse transcriptase inhibiting activity [24]. 3,9-Dihydro-9-dioxo-5H-imidazo(1,2-A) purine nucleosides synthesized from these nucleosides have shown improved anti-HIV activity [25].

In the present study, models of diverse nature have been developed through decision tree (DT), random forest (RF), support vector machine (SVM), and moving average analysis (MAA) using molecular descriptors (MDs) as independent variables for the prediction of the anti-HIV activity of purine nucleoside analogs in human peripheral blood mononuclear (PBM) cells.

\section{Methods}

Dataset

A dataset comprising 36 purine nucleoside analogs was selected for the present investigation (Fig. 1 and Table 1). The anti-HIV activity of these analogs in human PBM cells has been reported in terms of $\mathrm{EC}_{50}$ (effective concentration against $50 \%$ of cell population) by Amblard et al. [25]. The nucleoside analog DXZ possessing an $\mathrm{EC}_{50}$ value of $0.51 \mu \mathrm{M}$ is well known for its anti-HIV activity. DXZ was considered as a reference compound [24]. Accordingly, analogs possessing $\mathrm{EC}_{50}$ values of $\leq 0.51 \mu \mathrm{M}$ were considered to be active and analogs possessing $\mathrm{EC}_{50}$ values of $>0.51 \mu \mathrm{M}$ were considered to be inactive for the purpose of the present study.

\section{Molecular descriptors}

The MDs used in the current study include constitutional, physico-chemical, topostructural, topochemical, and topological charge indices, walk and path counts, information-based indices, and a wide variety of 3D descriptors. The majority of 2D and 3D MDs utilized in the present study were calculated using the Dragon software (version 5.3). Most of these MDs are reviewed in the textbook by Todeschini and Consonni [26]. An in-

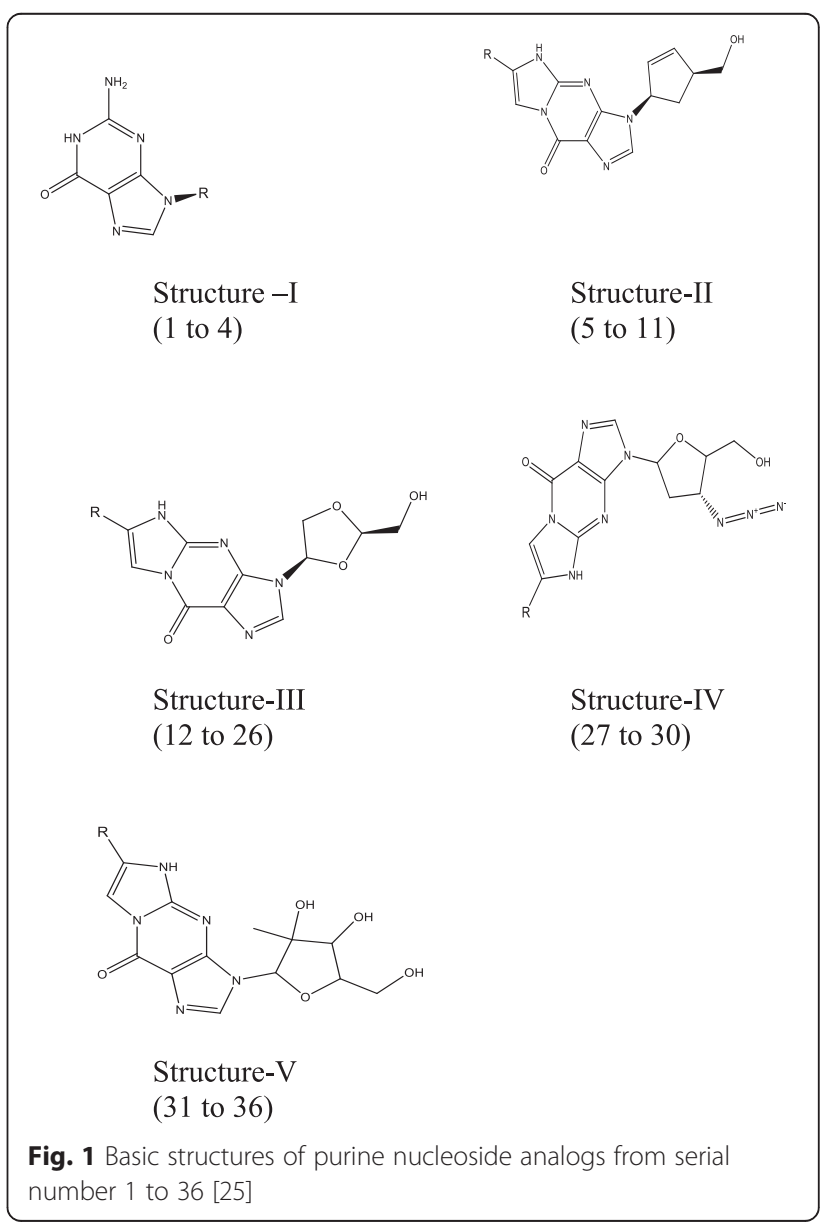


Table 1 Relationship between molecular descriptors and anti-HIV activity in human PBM cells

\begin{tabular}{|c|c|c|c|c|c|c|c|c|c|c|c|}
\hline \multirow[t]{3}{*}{$\begin{array}{l}\text { Serial } \\
\text { number }\end{array}$} & \multirow{3}{*}{$\begin{array}{l}\text { Basic } \\
\text { structure } \\
\text { of } \\
\text { compound }\end{array}$} & \multirow[t]{3}{*}{ Substituent (R) } & \multirow[t]{3}{*}{$A 2$} & \multirow[t]{3}{*}{ A4 } & \multirow[t]{3}{*}{ A23 } & \multirow[t]{3}{*}{ A37 } & \multicolumn{5}{|c|}{$\begin{array}{l}\text { Anti-HIV activity in human PBM cells } \\
\left(E_{50}\right)\end{array}$} \\
\hline & & & & & & & \multicolumn{4}{|c|}{ Predicted } & \multirow[t]{2}{*}{ Reported $[25$} \\
\hline & & & & & & & $\overline{\mathrm{A} 2}$ & A4 & $\mathrm{A} 23$ & A37 & \\
\hline 1 & । & 3-[4-(Hydroxymethyl)-2-cyclopent-1-yl] & 0.919 & 3.287 & 9.61 & 2.16 & + & + & \pm & - & + \\
\hline 2 & I & 3-(ß-D-1,3-Dioxolanyl) & 0.922 & 3.1 & 9.982 & 2.254 & + & + & \pm & - & + \\
\hline 3 & I & 3-(3-Azido-2,3-dideoxy- $\beta$-D-erythro-pentofuranosyl) & 0.903 & 4.599 & 50.599 & 2.197 & + & + & + & - & + \\
\hline 4 & । & 3-(ß-D-2-C-Methyl-ribofuranosyl) & 0.848 & 0.001 & 615.521 & 2.332 & - & - & - & - & - \\
\hline 5 & $\|$ & 4-MeO-Ph & 0.973 & 11.666 & 4.866 & 1.596 & - & - & - & - & - \\
\hline 6 & $\|$ & 4-Me-Ph & 0.972 & 11.15 & 5.338 & 1.614 & - & - & - & - & - \\
\hline 7 & $\|$ & $4-\mathrm{Br}-\mathrm{Ph}$ & 0.97 & 11.545 & 3.883 & 1.631 & - & - & - & - & - \\
\hline 8 & $\|$ & $4-\mathrm{NEt}_{2}-\mathrm{Ph}$ & 0.976 & 14.051 & 43.583 & 1.531 & - & - & + & + & + \\
\hline 9 & $\|$ & $4-\mathrm{NMe}_{2}-\mathrm{Ph}$ & 0.976 & 12.597 & 43.44 & 1.573 & - & - & + & + & + \\
\hline 10 & $\|$ & 2-Thiophenyl & 0.968 & 9.999 & 5.937 & 1.655 & - & - & - & - & - \\
\hline 11 & $\|$ & 3-Thiophenyl & 0.969 & 10.637 & 5.223 & 1.641 & - & - & - & - & - \\
\hline 12 & III & Et & 0.945 & 6.157 & 7.307 & 1.938 & - & - & - & - & - \\
\hline 13 & III & $\mathrm{Ph}$ & 0.971 & 9.869 & 2.313 & 1.674 & - & - & - & - & - \\
\hline 14 & III & 4-MeO-Ph & 0.974 & 11.602 & 4.849 & 1.627 & - & - & - & - & - \\
\hline 15 & III & 3-MeO-Ph & 0.974 & 10.545 & 5.38 & 1.652 & - & - & - & - & - \\
\hline 16 & III & 2-MeO-Ph & 0.97 & 9.834 & 6.121 & 1.678 & - & - & - & - & - \\
\hline 17 & III & 4-Me-Ph & 0.973 & 11.081 & 5.436 & 1.648 & - & - & - & - & - \\
\hline 18 & III & 4-Cl-Ph & 0.971 & 11.307 & 4.712 & 1.661 & - & - & - & - & - \\
\hline 19 & III & 4-F-Ph & 0.971 & 10.929 & 5.132 & 1.655 & - & - & - & - & - \\
\hline 20 & III & 2,4-F-Ph & 0.971 & 10.969 & 35.94 & 1.672 & - & - & \pm & - & - \\
\hline 21 & III & 4-NEt $-\mathrm{Ph}$ & 0.974 & 13.458 & 44.566 & 1.555 & - & - & + & + & + \\
\hline 22 & III & $4-\mathrm{NMe}_{2}-\mathrm{Ph}$ & 0.976 & 12.544 & 44.599 & 1.601 & - & - & + & - & - \\
\hline 23 & III & 2-Thiophenyl & 0.969 & 9.92 & 6.049 & 1.69 & - & - & - & - & - \\
\hline 24 & III & 3-Thiophenyl & 0.97 & 9.951 & 5.261 & 1.675 & - & - & - & - & - \\
\hline 25 & III & $4-\mathrm{N}_{3}-\mathrm{Ph}$ & 0.961 & 12.091 & 4.532 & 1.611 & - & - & - & - & - \\
\hline 26 & III & 4-CN-Ph & 0.975 & 12.57 & 4.893 & 1.626 & - & - & - & - & - \\
\hline 27 & IV & $\mathrm{Ph}$ & 0.939 & 0.566 & 6.494 & 1.645 & - & - & - & - & - \\
\hline 28 & IV & 4-MeO-Ph & 0.889 & 1.923 & 39.143 & 1.609 & - & - & \pm & - & - \\
\hline 29 & IV & 4-NEt $\mathrm{t}_{2}-\mathrm{Ph}$ & 0.907 & 4.048 & 357.424 & 1.551 & + & + & + & + & + \\
\hline 30 & IV & $4-\mathrm{NMe}_{2}-\mathrm{Ph}$ & 0.901 & 2.76 & 344.712 & 1.589 & + & + & + & + & + \\
\hline 31 & V & Et & 0.878 & 0.018 & 993.843 & 1.986 & - & - & - & - & - \\
\hline 32 & V & 4-MeO-Ph & 0.937 & 0.982 & 1972.793 & 1.663 & - & - & - & - & - \\
\hline 33 & V & 4-NEt $\mathrm{t}_{2}-\mathrm{Ph}$ & 2.345 & 0.94 & $16,083.229$ & 1.594 & - & - & - & - & - \\
\hline 34 & V & $4-\mathrm{NMe}_{2}-\mathrm{Ph}$ & 0.983 & 0.939 & $12,785.121$ & 1.639 & - & - & - & - & - \\
\hline 35 & V & 2-Thiophenyl & 0.123 & 0.923 & 2081.689 & 1.72 & - & - & - & - & - \\
\hline 36 & V & 3-Thiophenyl & 0.122 & 0.923 & 2059.054 & 1.706 & - & - & - & - & - \\
\hline
\end{tabular}

+ , active; - , inactive; \pm , transitional

house computer program was also employed to calculate MDs which were not included in the Dragon software. Initially, MDs with significant degenerate values were omitted from the large pool of MDs calculated through both the Dragon software and the in-house computer program. For the remaining MDs, a pairwise correlation analysis was carried out (one of any two indices with $r \geq$ 0.90 was excluded to minimize redundant information). The abovementioned exclusion technique was utilized to decrease the correlation and collinearity between MDs. 
Finally, 60 MDs, enlisted in Table 2, were short-listed for the development of models.

\section{Statistical methods Decision tree}

DT is a common method that provides both classification and predictive functions simultaneously. A single DT was grown for the prediction of anti-HIV activity and to identify the importance of various MDs used for the present study. A cutoff value dividing the compounds of the dataset into active and inactive with regard to anti-HIV activity was assigned to each MD for every compound. Then, a single MD is identified that split the entire training set into two or more homogenous subsets and shows the lowest possible false assignment before being chosen as parent node. The molecules at each parent node are classified, based on the MD value, into two child nodes, and the resulting child nodes or subsets are split into sub-subsets, generally using different MDs. The majority vote of the molecules reaching the same terminal node in the training set decides the prediction for a molecule to reach a given terminal node. In this manner, DT created an interactive branching topology in which the branch taken at each intersection is determined by a rule related to a MD of the molecule, and lastly, each terminating leaf of the tree is assigned to a particular category, i.e., A (active) or B (inactive) [27-30]. In the present study, RPART library was added in $\mathrm{R}$ program (version 2.10.1) to grow DT.

\section{Random forest}

$\mathrm{RF}$ is a well-known ensemble of unpruned trees generated through the systematic use of bootstrap samples of the training data for building forests (multiple trees) and random subsets of variables to facilitate the best possible bifurcation at each node [31, 32]. In the present study, the RFs were grown with the R program (version 2.10.1) using the random forest library.

\section{Support vector machine}

SVM is a relatively new classification technique. SVM involves drawing a boundary between groups of samples that fall into different classes. The SVM methodology comprised reducing the pool of 30 descriptors to a smaller size by eliminating the related variables, followed by development of classification models [33, 34]. Statistica v. 7.0 was used for the generation of SVM models. The classification models were generated using the training set of compounds followed by the validation of the best model using the test set of compounds [35]. Every third compound of the dataset was included in the test set. SVM model validity was also checked by cross-validation, i.e., leave-one-out method. SVM models were also validated by tenfold cross-
Table 2 List of molecular descriptors

\begin{tabular}{|c|c|}
\hline Code & Name of descriptor \\
\hline A1 & Eccentricity index, ECC \\
\hline A2 & Spherocity index, SPH \\
\hline A3 & Molecular connectivity topochemical index, $X^{A}$ \\
\hline A4 & Shape profile no. 20, SP20 \\
\hline A5 & Shape profile no. 07, SP07 \\
\hline A6 & Shape profile no. 08, SP08 \\
\hline A7 & Eccentric adjacency topochemical index \\
\hline A8 & $\begin{array}{l}\text { Radial distribution function - 10.5/weighted by atomic masses, } \\
\text { RDF105m }\end{array}$ \\
\hline A9 & Second Zagreb index M2, ZM2 \\
\hline A10 & Augmented eccentric connectivity topochemical index, ${ }^{A} \xi^{C}$ \\
\hline A11 & Mean information content on the distance magnitude, IDM \\
\hline $\mathrm{A} 12$ & Molecular profile no. 10, DP10 \\
\hline A13 & Molecular profile no. 11, DP11 \\
\hline A14 & Molecular profile no. 12, DP12 \\
\hline A15 & Molecular profile no. 13, DP13 \\
\hline A16 & Molecular profile no. 14, DP14 \\
\hline A17 & Radius of gyration (mass weighted), RGyr \\
\hline A18 & Eccentric connectivity topochemical index, $\xi^{c}$ \\
\hline A19 & Connective eccentricity topochemical index, $C^{\xi}$ \\
\hline A20 & Average vertex distance degree, VDA \\
\hline A21 & Mean square distance index (Balaban), MSD \\
\hline A22 & Schultz molecular topological index, SMTI \\
\hline A23 & Superaugmented pendentic topochemical index- $4,{ }^{S A} \rho^{p-4 c}$ \\
\hline A24 & Gutman MTI by valence vertex degrees, GMTIV \\
\hline A25 & Xu index, Xu \\
\hline A26 & Mean Wiener index, WA \\
\hline A27 & Superadjacency topochemical index, $\int^{A C}(G)$ \\
\hline A28 & Harary $\mathrm{H}$ index, Har \\
\hline A29 & Quasi-Wiener index (Kirchhoff number), QW \\
\hline $\mathrm{A} 30$ & First Mohar index, Tl1 \\
\hline A31 & Weiner's topochemical index, $W_{c}$ \\
\hline A32 & Reciprocal hyper-detour index, Rww \\
\hline A33 & Distance/detour index, D/D \\
\hline A34 & All-path Wiener index, Wap \\
\hline A35 & Superaugmented eccentric connectivity topochemical index-3, ${ }^{S A c} \xi c$ \\
\hline A36 & $\begin{array}{l}\text { Wiener-type index from Z-weighted distance matrix } \\
\text { (Barysz matrix), WhetZ }\end{array}$ \\
\hline A37 & $\begin{array}{l}\text { Balaban-type index from Z-weighted distance matrix (Barysz matrix), } \\
\text { JhetZ }\end{array}$ \\
\hline A38 & Maximal electrotopological negative variation, MAXDN \\
\hline A39 & Molecular electrotopological variation, DELS \\
\hline A40 & Superaugmented eccentric connectivity topochemical index-4, ${ }^{S A c} \xi_{4}^{c}$ \\
\hline A41 & Three-path Kier alpha-modified shape index, S3K \\
\hline A42 & Centralization, CENT \\
\hline
\end{tabular}


Table 2 List of molecular descriptors (Continued)

\begin{tabular}{|c|c|}
\hline A43 & Distance/detour ring index of order 9, D/Dr09 \\
\hline A44 & Molecular connectivity index, $X$ \\
\hline A45 & $\begin{array}{l}\text { Eigenvalue } 11 \text { from edge adjacency matrix weighted by } \\
\text { resonance integrals, EEig11r }\end{array}$ \\
\hline A46 & Average geometric distance degree, AGDD \\
\hline A47 & Absolute eigenvalue sum on geometry matrix, SEig \\
\hline A48 & Eccentric adjacency index, $\xi^{A}$ \\
\hline A49 & 3D-MoRSE - signal 26/unweighted, Mor26u \\
\hline A50 & $\begin{array}{l}\text { 3D-MoRSE - signal 25/weighted by atomic Sanderson } \\
\text { electronegativities, Mor25e }\end{array}$ \\
\hline A51 & Augmented eccentric connectivity index, ${ }^{A} \xi^{c}$ \\
\hline A52 & First component size directional WHIM index/unweighted, L1u \\
\hline A53 & $\begin{array}{l}\text { K global shape index/weighted by atomic Sanderson } \\
\text { electronegativities, Ke }\end{array}$ \\
\hline A54 & Superpendentic index, $\int P$ \\
\hline A55 & Mean information content on the leverage magnitude, HIC \\
\hline A56 & $H$ total index/weighted by atomic van der Waals volumes, HTV \\
\hline A57 & $\begin{array}{l}R \text { maximal autocorrelation of lag } 1 \text { /weighted by atomic } \\
\text { Sanderson electronegativities, R1e+ }\end{array}$ \\
\hline A58 & $R$ total index/weighted by atomic polarizabilities, RTp \\
\hline A59 & Superaugmented eccentric connectivity index-1, ${ }^{S A} \xi_{1}^{c}$ \\
\hline A60 & Weiner's index, $W$ \\
\hline
\end{tabular}

Most of the Dragon descriptors are largely defined in ref. [26]

validation. The kernel type that was adopted in the present work was the polynomial function. The first task was the assignment of each molecule to one class, namely 'actives' or 'inactives' based on the cutoff value $\left(\mathrm{EC}_{50}=0.51 \mu \mathrm{M}\right)$ of the reference compound.

\section{Moving average analysis}

MAA was utilized so as to facilitate the construction of single MD-based models for predicting the anti-HIV activity of purine nucleoside analogs. For the selection and evaluation of range-specific characteristics, exclusive activity ranges were determined from the frequency distribution of therapeutic response level. This was accomplished by initially plotting the relationship between index values and anti-HIV activity and subsequently identifying the active range by scrutinizing the resultant data by maximization of moving average with regard to active purine nucleoside analogs $(<35 \%=$ inactive, $35 \%$ to $65 \%=$ transitional, and $>65 \%=$ active) [36]. Biological activity was assigned to each analog involved in the dataset, which was subsequently compared with the reported anti-HIV activity (Table 1). Average values of $\mathrm{EC}_{50}$ and selectivity index (SI) were calculated for each range of the proposed models.

\section{Model validation}

DT-based models were validated using the tenfold cross-validation (CV) method [37]. The performance of the proposed models was evaluated by calculating the overall accuracy of prediction, sensitivity, specificity, non-error rate (arithmetic mean of sensitivity and specificity) [38, 39], and Matthews correlation coefficient (MCC) [40]. MCC is generally regarded as being one of the best statistical techniques which account for both over- and underprediction. MCC takes both sensitivity and specificity into account, and its value ranges from -1 to +1 . Higher values of MCC indicate better predictions $[41,42]$. The statistical importance of MDs used in building predictive models was also appraised by intercorrelation analysis. The degree of correlation was appraised by Spearman's rank correlation coefficient ' $r$ '. Pairs of MDs with $r \geq 0.97$ are considered to be highly inter-correlated while those with $0.68 \leq r \leq 0.97$ to be appreciably correlated; MDs with $0.36 \leq r \leq 0.67$ are weakly correlated whereas the pairs of MDs with low $r$ values $(<0.35)$ are not inter-correlated [43, 44].

\section{Results and discussion}

AIDS is the fourth leading cause of death worldwide. Inhibition of the human immunodeficiency virus and sustained suppression of viral replication reduce morbidity and prolong life in patients with HIV infection. This virus is therefore a major target for the structure-based inhibitors design.

Finding that the structure of a molecule has an important role in its therapeutic activity coupled with the need for safer potent drugs to be developed with minimum animal sacrifice, expenditure, and time loss has led to the origin of structure-activity relationship (SAR) studies [45]. The inherent problem in the development of a suitable correlation between chemical structures and biological activity can be attributed to the nonquantitative nature of chemical structures. MDs translate chemical structures into characteristic numerals and facilitate (Q)SAR studies [46, 47].

In the present study, the relationship between antiHIV activity and the structure of purine nucleoside analogs has been investigated and suitable models developed using diverse classification techniques, i.e., DT, RF, SVM, and MAA. DT was built from a set of 60 MDs enlisted in Table 2. The MD at the originating node is the most significant, and the significance of MD decreases with the gradual increase in the tree height [27-30]. The classification of purine nucleoside analogs as inactive and active using a single tree, based on the Balaban-type index from $Z$-weighted distance matrix, A37, Jhet $Z$ index, and mean information content on the distance magnitude, A11, IDM index, has 
been depicted in Fig. 2. The DT identified the Balabantype index from $Z$-weighted distance matrix, A37, Jhet $Z$ index, as the most important index.

A37, i.e., the Balaban-type index from $Z$-weighted distance matrix, Jhet $Z$ index, is based on the Barysz matrix and was developed by Barysz et al. It may be expressed as per the following:

$$
J_{\mathrm{B}}=\frac{q}{(\mu+1)} \sum_{\text {edges }}^{G}\left(\frac{1}{\sqrt{S_{i} S_{j}}}\right)
$$

where $S_{i} S_{j}$ represents the product of the distance sums of the adjacent pairs of vertices $i$ and $j$ in a graph $G$. The cycloatomic number of the graph is represented by $\mu$, and it indicates the number of independent cycles in the graph $[48,49]$.

The DT classified the analogs with an accuracy of $>99.9 \%$ in the training set. The sensitivity, specificity, non-error rate, overall accuracy of prediction, and MCC of the tenfold cross-validated set was of the order of $75 \%, 93 \%, 84 \%, 89 \%$, and 0.68, respectively (Table 3). A high value of MCC simply indicates the robustness of the proposed DT-based model.

A11, i.e., mean information content on the distance magnitude, IDM index, is one of the information indices reported by Bonchev et al. It may be expressed as per the following:

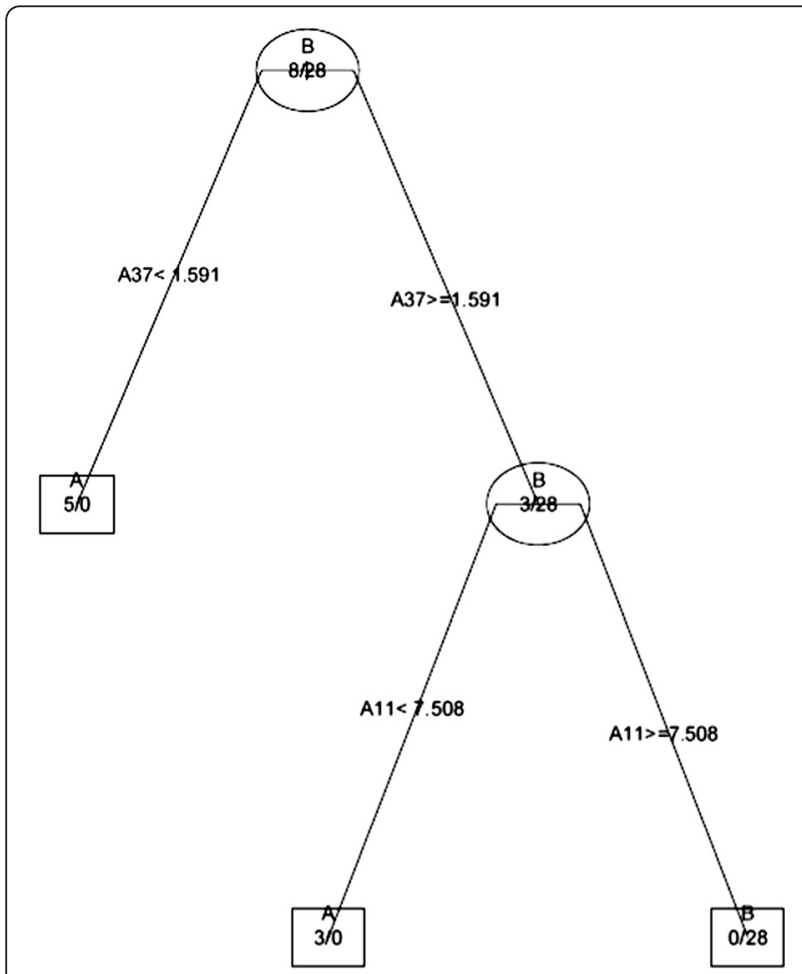

Fig. 2 A decision tree for distinguishing active purine nucleoside analogs (A) from inactive analogs (B)

$$
\overline{\mathrm{I}}_{D}^{W}=-\sum_{n=1}^{G}\left(k_{n} \frac{n}{W} \log _{2} \frac{n}{W}\right)
$$

where $W$ is the Wiener index, $k_{n}$ is the number of distances of equal $n$ value in the triangular submatrix $D$, and $G$ is the maximum distance value [50].

The RFs were grown utilizing $60 \mathrm{MDs}$ as enlisted in Table 1. The RF classified purine nucleoside analogs with regard to anti-HIV activity with an accuracy of $83 \%$ and the out-of-bag (OOB) estimate of error was $17 \%$. The sensitivity, specificity, non-error rate, accuracy of prediction, and MCC value of the RF-based model for the tenfold cross-validated set were found to be $62.5 \%, 89 \%, 75.7 \%$, $83 \%$, and 0.52 , respectively (Table 3 ). A high value of MCC simply indicates the robustness of the proposed RFbased model.

SVM-based classification models were built utilizing a small pool of topological descriptors as specified in the Methods section. The dataset was divided into a training and a test set based on a random test set selection comprising 27 compounds in the training and 9 compounds in the test set, respectively. The models were built using the training set molecules and subsequently validated by test set molecules. The SVM model for the training set resulted in a specificity of $100 \%$ and an accuracy of prediction of $93 \%$. The sensitivity, specificity, non-error rate, overall accuracy of prediction, and MCC of the test set was of the order of $50 \%, 86 \%, 68 \%, 78 \%$, and 0.36 , respectively (Table 3 ).

Four single index-based models were developed using MAA (Table 4). The Balaban-type index from $Z$ weighted distance matrix: index A37, identified as the most important index by the decision tree, was used to construct a model for the prediction of the anti-HIV activity of purine nucleoside analogs. Three more indices, i.e., spherocity index, SPH, A2; shape profile no. 20, SP20, A4; and superaugmented pendentic topochemical index-4, ${ }^{S A} f^{P-4 c}$, A23, were also used to develop the models for predicting the anti-HIV activity of purine nucleoside analogs.

A2, i.e., spherocity index, SPH, is one of the geometrical descriptors given by Robinson et al. and may be expressed as:

$$
\Omega_{\mathrm{SPH}}=\frac{3 \lambda_{3}}{\left(\lambda_{1}+\lambda_{2}+\lambda_{3}\right)} \quad 1 \geq \Omega_{\mathrm{SPH}} \geq 0
$$

where $\lambda_{1}, \lambda_{2}$, and $\lambda_{3}$ are the eigenvalues of the autocovarience matrix used in the principal component analysis of the molecule. The $\Omega_{\mathrm{SPH}}$ value ranges from unity for totally spherical molecules to zero for totally flat molecules [51].

A4, i.e., shape profile no. 20, SP20, is one of the Randic molecular profiles described by Randic and may be expressed as: 
Table 3 Confusion matrix for anti-HIV activity of purine nucleoside analogs in human PBM cells

\begin{tabular}{|c|c|c|c|c|c|c|c|c|c|}
\hline \multirow[t]{2}{*}{ Model } & \multirow[t]{2}{*}{ Description } & \multirow[t]{2}{*}{ Ranges } & \multicolumn{2}{|c|}{ Number of compounds predicted } & \multirow{2}{*}{$\begin{array}{l}\text { Sensitivity } \\
(\%)\end{array}$} & \multirow{2}{*}{$\begin{array}{l}\text { Specificity } \\
(\%)\end{array}$} & \multirow{2}{*}{$\begin{array}{l}\text { Non- } \\
\text { error } \\
\text { rate } \\
(\%)\end{array}$} & \multirow{2}{*}{$\begin{array}{l}\text { Overall } \\
\text { accuracy } \\
\text { of } \\
\text { prediction } \\
\text { (\%) }\end{array}$} & \multirow[t]{2}{*}{ MCC } \\
\hline & & & Active & Inactive & & & & & \\
\hline \multirow[t]{4}{*}{ Decision tree } & \multirow[t]{2}{*}{ Training set } & Active & 08 & 00 & \multirow[t]{2}{*}{100} & \multirow[t]{2}{*}{100} & \multirow[t]{2}{*}{100} & \multirow[t]{2}{*}{$>99.9$} & \multirow[t]{2}{*}{1.00} \\
\hline & & Inactive & 00 & 28 & & & & & \\
\hline & \multirow[t]{2}{*}{ Tenfold cross-validated set } & Active & 06 & 02 & \multirow[t]{2}{*}{75} & \multirow[t]{2}{*}{93} & \multirow[t]{2}{*}{84} & \multirow[t]{2}{*}{89} & \multirow[t]{2}{*}{0.68} \\
\hline & & Inactive & 02 & 26 & & & & & \\
\hline \multirow[t]{2}{*}{ Random forest } & & Active & 05 & 03 & \multirow[t]{2}{*}{62.5} & \multirow[t]{2}{*}{89} & \multirow[t]{2}{*}{75.7} & \multirow[t]{2}{*}{83} & \multirow[t]{2}{*}{0.52} \\
\hline & & Inactive & 03 & 25 & & & & & \\
\hline \multirow[t]{4}{*}{ Support vector machine } & \multirow[t]{2}{*}{ Training set } & Active & 04 & 02 & \multirow[t]{2}{*}{66.7} & \multirow[t]{2}{*}{100} & \multirow[t]{2}{*}{83.3} & \multirow[t]{2}{*}{93} & \multirow[t]{2}{*}{0.78} \\
\hline & & Inactive & 00 & 21 & & & & & \\
\hline & \multirow[t]{2}{*}{ Test set } & Active & 01 & 01 & \multirow[t]{2}{*}{50} & \multirow[t]{2}{*}{86} & 68 & 78 & 0.36 \\
\hline & & Inactive & 01 & 06 & & & & & \\
\hline
\end{tabular}

The recognition rate of decision tree-, random forest-, and support vector machine-based models is also shown

$$
\begin{aligned}
& S=N+{ }^{1} R x+{ }^{2} R / 2 ! x^{2}+{ }^{3} R / 3 ! x^{3} \\
& +{ }^{4} R / 4 ! x^{4} \ldots \ldots{ }^{n} R / n ! x^{n} \\
& S={ }^{1} S,{ }^{2} S,{ }^{3} S, \quad{ }^{4} S \ldots \quad \ldots{ }^{n} S
\end{aligned}
$$

where $N$ is a constant indicating the size of the system.

${ }^{1} R,{ }^{2} R,{ }^{3} R \ldots$ are the averages of the row sums in the ${ }^{1} D$,
${ }^{2} D,{ }^{3} D \ldots$ matrix, respectively. $D$ is the geometry distance matrix of a structure [52].

A23, i.e., superaugmented pendentic topochemical index-4, is the topochemical version of the topological descriptor (superaugmented pendentic index-4) reported by Dureja et al. [53]. Superaugmented pendentic index-4 is

\begin{tabular}{|c|c|c|c|c|c|c|c|c|c|c|c|}
\hline \multirow[t]{2}{*}{ Descriptor } & \multirow{2}{*}{$\begin{array}{l}\text { Nature of } \\
\text { range in the } \\
\text { proposed } \\
\text { model }\end{array}$} & \multirow[t]{2}{*}{$\begin{array}{l}\text { Descriptor } \\
\text { value }\end{array}$} & \multicolumn{2}{|c|}{$\begin{array}{l}\text { Number of compounds } \\
\text { in each range }\end{array}$} & \multirow[t]{2}{*}{$\begin{array}{l}\text { Sensitivity } \\
(\%)\end{array}$} & \multirow[t]{2}{*}{$\begin{array}{l}\text { Specificity } \\
(\%)\end{array}$} & \multirow{2}{*}{$\begin{array}{l}\text { Non- } \\
\text { error } \\
\text { rate } \\
(\%)\end{array}$} & \multirow{2}{*}{$\begin{array}{l}\text { Overall } \\
\text { accuracy } \\
\text { of } \\
\text { prediction } \\
\text { (\%) }\end{array}$} & \multirow[t]{2}{*}{ MCC } & \multirow{2}{*}{$\begin{array}{l}\text { Average } \\
\mathrm{EC}_{50}(\mu \mathrm{M}) \text { of } \\
\text { correctly } \\
\text { predicted } \\
\text { compounds } \\
\text { in each } \\
\text { range }\end{array}$} & \multirow{2}{*}{$\begin{array}{l}\text { Average SI } \\
\text { of correctly } \\
\text { predicted } \\
\text { compounds } \\
\text { in each } \\
\text { range }\end{array}$} \\
\hline & & & Total & $\begin{array}{l}\text { Correctly } \\
\text { predicted }\end{array}$ & & & & & & & \\
\hline \multirow[t]{3}{*}{ A2 } & $\begin{array}{l}\text { Lower } \\
\text { inactive }\end{array}$ & $<0.901$ & 3 & 3 & 63 & 100 & 81.5 & 91.7 & 0.75 & 67.1 & 15.205 \\
\hline & Active & 0.901 to 0.922 & 5 & 5 & & & & & & 0.182 & 825.741 \\
\hline & $\begin{array}{l}\text { Upper } \\
\text { inactive }\end{array}$ & $>0.922$ & 28 & 25 & & & & & & 33.613 & 66.665 \\
\hline \multirow[t]{3}{*}{ A4 } & $\begin{array}{l}\text { Lower } \\
\text { inactive }\end{array}$ & $<2.76$ & 9 & 9 & 63 & 100 & 81.5 & 91.7 & 0.75 & 78.855 & 6.544 \\
\hline & Active & 2.76 to 4.599 & 5 & 5 & & & & & & 0.182 & 825.741 \\
\hline & $\begin{array}{l}\text { Upper } \\
\text { inactive }\end{array}$ & $>4.599$ & 22 & 19 & & & & & & 17.47 & 43.186 \\
\hline \multirow[t]{4}{*}{ A23 } & $\begin{array}{l}\text { Lower } \\
\text { inactive }\end{array}$ & $<9.61$ & 18 & 18 & 100 & 96 & 98 & 96.9 & 0.91 & 18.056 & 36.560 \\
\hline & Transitional & 9.61 to 43.43 & 4 & NA & & & & & & 4.138 & 102.32 \\
\hline & Active & $\begin{array}{l}43.44 \text { to } \\
357.424\end{array}$ & 7 & 6 & & & & & & 0.141 & 859.542 \\
\hline & $\begin{array}{l}\text { Upper } \\
\text { inactive }\end{array}$ & $>357.424$ & 7 & 7 & & & & & & 100 & 100 \\
\hline \multirow[t]{2}{*}{ A37 } & Active & 1.531 to 1.589 & 5 & 5 & 63 & 100 & 81.5 & 91.7 & 0.75 & 0.134 & 920.339 \\
\hline & Inactive & $>1.589$ & 24 & 21 & & & & & & 37.201 & 31.408 \\
\hline
\end{tabular}
expressed as:

Table 4 Proposed MAA models for the prediction of anti-HIV activity of PNAs in human PBM cells 


$$
S A \int^{P-4}\left(G_{k, n}\right)=\sum_{i=1}^{n} \frac{p_{i} m_{i}}{e_{i}^{4}}
$$

Superaugmented pendentic topochemical index-4 may be defined as the summation of the quotients of the product of all the non-zero row elements in the chemical pendent matrix and product of chemical adjacent vertex degrees and the fourth power of the chemical eccentricity of the concerned vertex for all vertices in a hydrogen-suppressed chemical molecular graph and may be expressed as:

$$
S A \int^{P-4}\left(G_{k, n}\right)^{c}=\sum_{i=1}^{n} \frac{p_{i c} m_{i c}}{e_{i c}^{4}}
$$

where $p_{i c}$ is the chemical pendenticity and is obtained by multiplying all the non-zero row elements in the chemical pendent matrix, $\Delta P c$, of a chemical graph $\left(G_{k}, n\right) c$. $\triangle P c$ is a sub-matrix of the chemical distance matrix and is obtained by retaining the columns corresponding to pendent vertices. $m_{i c}$ is the augmented chemical adjacency and is defined as the product of chemical degrees of all the vertices $v_{j}$ adjacent to vertex $v_{i}$. $e_{i c}$ is the chemical eccentricity of vertex $v_{i}$, and $n$ is the number of vertices in graph $G$ [54-56].

The results of the intercorrelation analysis (Table 5) reveal that the pairs A2:A23 and A23:A37 were not correlated while the pairs A4:A23, A4:A37, and A2:A37 were found to be weakly correlated. The accuracy of prediction for all the four MAA-based models varies from 91.7 to $96.9 \%$, indicating high predictability (Table 4).

The average $\mathrm{EC}_{50}$ value of the correctly predicted analogs in the active ranges in MAA-based models varied from 0.134 to $0.182 \mu \mathrm{M}$. Such a low average $\mathrm{EC}_{50}$ value signifies high potency of the active ranges (Fig. 3).

Drug safety evaluation is the key part of drug discovery and development process to identify those that have an appropriately balanced safety-efficacy profile for a given indication [57]. The therapeutic index (TI), certain safety factor (CSF), protective index (PI), therapeutic window (TW), and selectivity index (SI) are some of such important parameters that can be used to achieve this balance. TI may be defined as the ratio of $\mathrm{LD}_{50} / \mathrm{ED}_{50}$, where $\mathrm{LD}_{50}$ is defined as the single dose of a therapeutic agent that can be likely to cause death in $50 \%$ of the animal population and $\mathrm{ED}_{50}$ is defined as the single dose

Table 5 Intercorrelation matrix

\begin{tabular}{lllll}
\hline & A2 & A4 & A23 & A37 \\
\hline A2 & 1.00 & 0.85 & -0.13 & -0.62 \\
A4 & & 1.00 & -0.39 & -0.47 \\
A23 & & 1.00 & -0.11 \\
A37 & & & & 1.00 \\
\hline
\end{tabular}

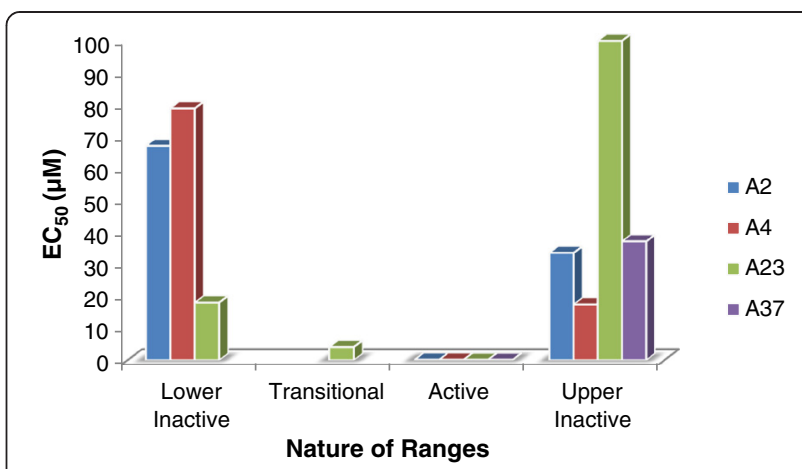

Fig. 3 Average $\mathrm{EC}_{50}$ of anti-HIV activity of correctly predicted PNAs in various ranges of MAA-based models

of a therapeutic agent that can be likely to cause a particular effect to occur in $50 \%$ of the animal population [58-60]. Similarly, SI is calculated for a drug molecule in the case of cell studies, and it may be defined as the ratio of $\mathrm{CC}_{50}$ to $\mathrm{EC}_{50}$, where $\mathrm{CC}_{50}$ and $\mathrm{EC}_{50}$ represent cytotoxic and effective concentrations, respectively. It is an indirect measure of the safety of a drug. A high value of SI simply indicates low toxicity and more safety. A high value of SI is a desirable property for any drug candidate so as to minimize toxicity. Therefore, such safety parameters should be determined in the initial stages of the drug discovery process to avoid much costlier latestage failures [61]. Active ranges of the proposed MAAbased models exhibited high degree of selectivity towards infected human PBM cells as indicated by a greater value of SI for active ranges compared to inactive ranges (Fig. 4). As a consequence, active ranges identified by MAA models have both the desired requirements of a drug molecule, i.e., high potency and safety. Model validation by confusion matrix shows the sensitivity of the models of the order of $63 \%$ to $100 \%$ (Table 4). High values of MCC simply indicate the robustness of the proposed MAA-based models.

The present modeling studies may be of great utility for providing lead molecules through exploitation of

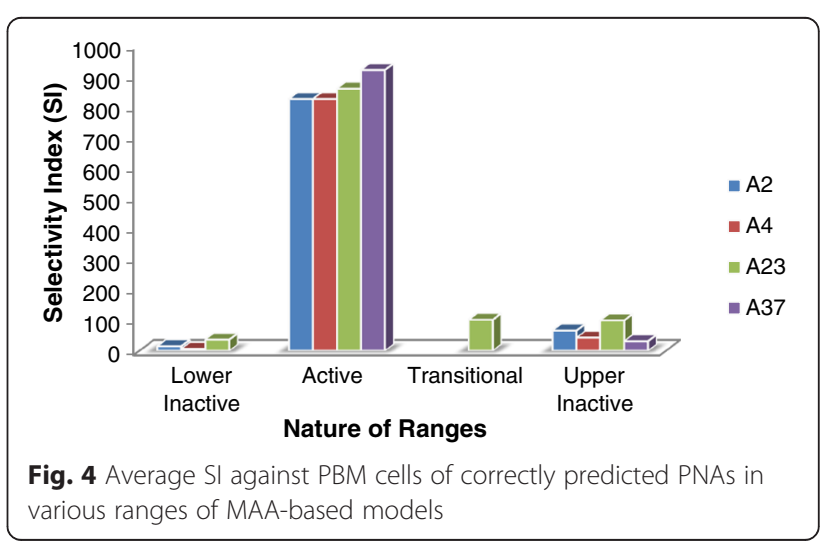


active ranges in single MD-based models. The proposed models are unique and differ widely from conventional QSAR models. Both systems of modeling have their advantages and limitations. In the instant modeling, the system adopted has a distinct advantage of identification of narrow active ranges, which may be erroneously skipped during regression analysis in conventional QSAR. Since the ultimate goal of modeling is to provide lead structures, therefore, active ranges of the proposed models can play a vital role in providing lead structures [62]. Therefore, active ranges of the proposed models can naturally play a vital role in providing lead structures.

\section{Conclusions}

Diverse techniques such as DT, RF, SVM, and MAA were successfully used to develop models for anti-HIV purine nucleoside analogs. Models based on DT, RF, and SVM statistical approaches show an accuracy of prediction up to the order of $89 \%$. The overall accuracy of prediction of MAA-based models varies from $91.7 \%$ to $96.9 \%$ with regard to the anti-HIV activity of purine nucleoside analogs in human PBM cells. High values of sensitivity, specificity, and MCC indicate the robustness of the proposed models. Good predictability, high potency, and safety of the active ranges in the proposed MAA-based models will naturally provide ease in furnishing lead structures for the development of potent but safe anti-HIV purine nucleoside analogs.

\section{Competing interests}

The authors declare that they have no competing interests.

\section{Authors' contributions \\ AKM proposed the subject, designed the study and supervised the entire work. Major work was carried out by NK. Modeling through support vector machine was carried out by VL. NK prepared the draft of the manuscript. AKM modified the manuscript. All the authors read and approved the final manuscript.}

\section{Author details}

${ }^{1}$ Faculty of Pharmaceutical Sciences, Pt. B. D. Sharma University of Health Sciences, Rohtak 124001, India. ${ }^{2} J$ CDM College of Pharmacy, Barnala Road, Sirsa 125055 , India.

Received: 12 May 2015 Accepted: 19 May 2015

Published online: 23 May 2015

\section{References}

1. Jurs P. Quantitative structure property relationships. In: Gasteiger J, editor. Handbook of chemoinformatics, vol. 3. Weinheim: Wiley-VCH; 2003. p. 1314-35.

2. Ivanciuc O. Drug design with artificial intelligence methods. In: Meyers RA, editor. Encyclopedia of complexity and systems science. Berlin: Springer; 2009. p. 2113-39.

3. Hansch C. On the structure of medicinal chemistry. J Med Chem. 1976;19(1):1-6

4. Bagchi MC, Maiti BC, Mills D, Basak SC. Usefulness of graphical invariants in quantitative structure-activity correlations of tuberculostatic drugs of the isonicotinic acid hydrazide type. J Mol Model. 2004;10:102-11.

5. Mon J, Flury M, Harsh JB. A quantitative structure-activity relationships (QSAR) analysis of triarylmethane dye tracers. J Hydrology. 2006;316:84-97.
6. Sabljic A. Quantitative modeling of soil sorption for xenobiotic chemicals. Environ Health Perspect. 1989;83:179-90.

7. Guidance on information requirements and chemical safety assessment Chapter R.6: QSARs and grouping of chemicals. https:/echa.europa.eu/documents/10162/ 13632/information requirements r6 en.pdf. Accessed 24 May 2015

8. International QSAR Foundation. http://www.tm.durusau.net/? $\mathrm{p}=13346$. Accessed 26 Aug 2012

9. Hansch C. A quantitative approach to biochemical structure activity relationships. Acc Chem Res. 1969;2:232-9.

10. Ivanciuc $\mathrm{O}$. Weka machine learning for predicting the phospholipidosis inducing potential. Curr Top Med Chem. 2008;8:1691-709.

11. Zhang S, Golbraikh A, Oloff S, Kohn H, Tropsha A. A novel automated lazy learning QSAR (ALL-QSAR) approach: method development, applications, and virtual screening of chemical databases using validated ALL-QSAR models. J Chem Inf Model. 2006:46:1984-95.

12. Plewczynski D, Von Grotthuss M, Spieser SAH, Rychlewski L, Wyrwicz LS, Ginalski K, et al. Target specific compound identification using a support vector machine. Comb Chem High Throughput Screen. 2007;10:189-96.

13. Klon $A E$, Diller DJ. Library fingerprints: a novel approach to the screening of virtual libraries. J Chem Inf Model. 2007;47:1354-65.

14. Vogt $\mathrm{M}$, Bajorath J. Introduction of an information-theoretic method to predict recovery rates of active compounds for Bayesian in silico screening: theory and screening trials. J Chem Inf Model. 2007;47:337-41.

15. Schneider N, Jäckels C, Andres C, Hutter MC. Gradual in silico filtering for druglike substances. J Chem Inf Model. 2008:48:613-28.

16. Modi S. Positioning ADMET in silico tools in drug discovery. Drug Discov Today. 2004;9:14-5.

17. Frank E, Hall M, Trigg L, Holmes $G$, Witten IH. Data mining in bioinformatics using Weka. Bioinformatics. 2004;20:2479-81.

18. Witten $\mathbb{I H}$, Frank E. Data mining: practical machine learning tools and techniques. 2nd ed. San Francisco: Morgan Kaufmann; 2005. p. 525.

19. Mjolsness E, DeCoste D. Machine learning for science: state of the art and future prospects. Science. 2001;293:2051-5.

20. Duch W, Swaminathan K, Meller J. Artificial intelligence approaches for rational drug design and discovery. Cur Pharm Des. 2007;13:1-12.

21. Stefania F, Maria LB, Laura DL, Angela R, Anna MM, Zeger D, et al. New 4-[(1-benzyl-1H-indol-3-yl)carbonyl]-3-hydroxyfuran-2(5H)-ones, $\beta$-diketo acid analogs as HIV-1 integrase inhibitors. Arch Pharm. 2007;340(6):292-8.

22. Glesby MJ. Drug development: an overview. 1998. http://www.acria.org/ files/ ACRIA \%20 Update \%20 Winter \%20 1998.pdf. Accessed 15 Mar 2012

23. Robak T, Lech-Maranda E, Korycka A, Robak E. Purine nucleoside analogs as immunosuppressive and antineoplastic agents: mechanism of action and clinical activity. Curr Med Chem. 2006;13(26):3165-89.

24. Parikh UM, Koontz DL, Chu CK, Schinazi RF, Mellors JW. In vitro activity of structurally diverse nucleoside analogs against human immunodeficiency virus type 1 with the K65R mutation in reverse transcriptase. Antimicrob Agents Chemother. 2005;49(3):1139-44.

25. Amblard F, Fromentin E, Detorio M, Obikhod A, Rapp KL, McBrayer TR, et al. Synthesis, antiviral activity and stability of nucleoside analogs containing tricyclic bases. Eur J Med Chem. 2009:44(10):3845-51.

26. Todeschini R, Consonni V. Handbook of molecular descriptors. Weinheim: Wiley-VCH; 2000.

27. Tong $W$, Hong $H$, Fang $H$, Xie $Q$, Perkins $R$. Decision forest: combining the predictions of multiple independent decision tree models. J Chem Inf Comp Sci. 2003:43:525-31.

28. Asikainen A, Kolehmainen M, Ruuskanen J, Tuppurainen K. Structure-based classification of active and inactive estrogenic compounds by decision tree, LVO and kNN methods. Chemosphere. 2006;62:658-73.

29. Wagener M, Geerestein VJ. Potential drugs and nondrugs: prediction and identification of important structural features. J Chem Inf Comp Sci. 2000;40:280-92.

30. Dureja H, Gupta S, Madan AK. Topological models for prediction of pharmacokinetic parameters of cephalosporins using random forest, decision tree and moving average analysis. Sci Pharm. 2008;76:377-94.

31. Zhang Q-U, Aires J. Random forest prediction of mutagenicity from empirical physicochemical descriptors. J Chem Inf Mod. 2007:47:1-8.

32. Prasad $A M$, Iverson $L R$, Liaw A. Newer classification and regression tree techniques: bagging and random forests for ecological prediction. Ecosystems. 2006;9:181-99.

33. Smola AJ, Schölkopf B. A tutorial on support vector regression. Stat Comput. 2004;14:199-222. 
34. Vapnik V, Lerner A. Pattern recognition using generalized portrait method. Autom Remote Control. 1963;24:774-80.

35. Sanchez VD. Advanced support vector machines and kernel methods. Neurocomputing. 2003;55:5-20.

36. Gupta S, Singh M, Madan AK. Predicting anti-HIV activity: computational approach using novel topological indices. J Comp Aided Mol Des. 2001;15:671-8.

37. McLachlan GJ, Do KA, Ambroise C. Analyzing microarray gene expression data. New York: Wiley; 2004.

38. Han L, Wang Y, Bryant SH. Developing and validating predictive decision tree models from mining chemical structural fingerprints and high-throughput screening data. BMC Bioinformatics. 2008;9:401.

39. Ballabio D, Consonni V. Classification tools in chemistry. Part 1: linear models. PLS-DA. Anal Methods. 2013;5:3790-8.

40. Matthews BW. Comparison of the predicted and observed secondary structure of T4 phage lysozyme. Biochim Biophys Acta. 1975;405:442-51.

41. Baldi P, Bruank S, Chauvin Y, Andersen CAF, Nielsen H. Assessing the accuracy of prediction algorithms for classification: an overview. Bioinformatics. 2000;16:412-24.

42. Carugo 0 . Detailed estimation of bioinformatics prediction reliability through the fragmented prediction performance plots. BMC Bioinformatics. 2007;8:380.

43. Mason RO, Lind DA, Marchal WG. Statistics: an introduction. New York: Harcourt Brace Jovanovich; 1983.

44. Congelosi VE, Taylor PE, Rice PF. Basic statistics: a real world approach. St Paul: West Publishing Co; 1983.

45. Martin YC. Quantitative drug design. New York: Dekker Press; 1978.

46. Balaban AT, Motoc J, Bonchev D, Mekennyan O. Topological indices for structure-activity correlations. Top Curr Chem. 1983;114:21-55.

47. Basak SC, Bertlsen S, Grunwald GD. Application of graph theoretical parameters in quantifying molecular similarity and structure activity relationships. J Chem Inf Comp Sci. 1994:34:270-6.

48. Balaban AT. Topological indices based on topological distances in molecular graphs. Pure Appl Chem. 1983;55:199-206.

49. Barysz M, Jashari G, Lall RS, Srivastava VK, Trinajstic N. On the distance matrix of molecules containing heteroatoms. In: King RB, editor. Chemical applications of topology and graph theory. Amsterdam: Elsevier; 1983. p. 222-7.

50. Bonchev D, Trinajsti N. Information theory, distance matrix and molecular branching. J Chem Phy. 1977;67(10):4517-33.

51. Robinson DD, Barlow TW, Richards WG. Reduced dimensional representations of molecular structure. J Chem Inf Comp Sci. 1997;37:939-42.

52. Randic M. Molecular shape profiles. J Chem Inf Comp Sci. 1995;35:373-82.

53. Dureja H, Kinkar CD, Madan AK. Superaugmented pendentic indices: novel topological descriptors for QSAR/QSPR. Sci Pharm. 2009;77:521-37.

54. Goel A, Madan AK. Structure-activity study on anti-inflammatory pyrazole carboxylic acid hydarzide analogs using molecular connectivity indices. J Chem Inf Comp Sci. 1995;35:510-4.

55. Kumar V, Sardana S, Madan AK. Predicting anti-HIV activity of 2,3-diaryl-1, 3-thiazolidin-4-ones: computational approach using reformed eccentric connectivity index. J Mol Mod. 2004;10:399-407.

56. Bajaj S, Sambi SS, Madan AK. Prediction of carbonic anhydrase activation by tri-/tetrasubstituted-pyridinium-azole drugs: a computational approach using novel topochemical descriptor. QSAR Comb Sci. 2004;23:506-14.

57. Muller PY, Milton MN. The determination and interpretation of the therapeutic index in drug development. Nat Rev Drug Discov. 2012;11:751-61.

58. Blazka ME. Acute toxicity and eye irritancy. In: Hayes AW, editor. Principles and methods of toxicology. 5th ed. Boca Raton: CRC Press Taylor and Francis Group; 2001. p. 1131-41.

59. Kevin CO, Trevor MP. Drug toxicity and poisoning. In: Goodman LS, Gilman A, editors. The pharmacological basis of therapeutics. 12th ed. New York: The McGraw-Hill Books; 2011. p. 73-89.

60. Simmons MA. Mechanisms of drug action and pharmacodynamics. In: Simmons MA, editor. Pharmacology: an illustrated review. New York: Thieme Medical Publishers; 2012. p. 26.

61. Madan AK, Bajaj S, Dureja H. Classification models for safe drug molecules. In: Reisfeld B, Mayeno AN, editors. Computational toxicology, Humana Press, vol. 2. New York: Springer Science + Business Media; 2013. p. 99-102.

62. Dureja H, Madan AK. Prediction of h5-HT2A receptor antagonistic activity of arylindoles: computational approach using topochemical descriptors. J Mol Graph Mod. 2006;25:373-9.

\section{Publish with ChemistryCentral and every scientist can read your work free of charge \\ "Open access provides opportunities to our colleagues in other parts of the globe, by allowing anyone to view the content free of charge." \\ W. Jeffery Hurst, The Hershey Company.}

- available free of charge to the entire scientific community

- peer reviewed and published immediately upon acceptance

- cited in PubMed and archived on PubMed Central

- yours - you keep the copyright

Submit your manuscript here:

http://www.chemistrycentral.com/manuscript/
()

Chemistry Central 